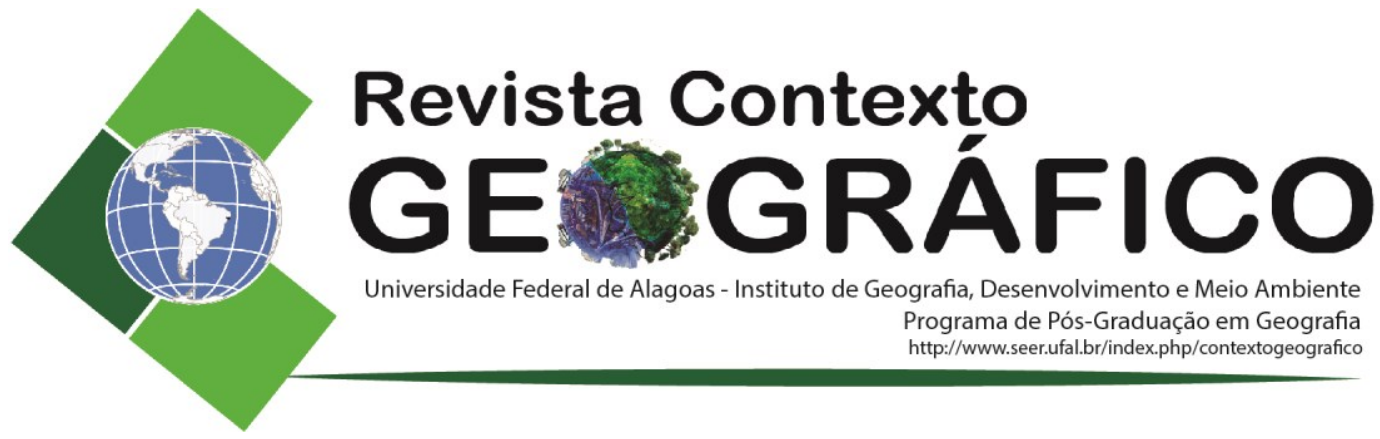

\title{
ÁREAS POTENCIAIS PARA PRESERVAÇÃO NA ÁREA DE PROTEÇÃo AMBIENTAL DE SANTA RITA, ALAGOAS
}

\author{
Esdras de Lima Andrade \\ Universidade Federal de Alagoas, Instituto de Geografia, Desenvolvimento e Meio Ambiente, \\ Maceió, AL, Brasil \\ esdras.andrade@,igdema.ufal.br \\ Alex Nazário Silva Oliveira \\ Universidade Federal de Alagoas, Instituto de Geografia, Desenvolvimento e Meio Ambiente, \\ Maceió, AL, Brasil \\ alexnazario@hotmail.com \\ Daniel Nivaldo da Conceição \\ Instituto do Meio Ambiente de Alagoas, Maceió, AL, Brasil \\ danieldaconceicao01@gmail.com
}

\begin{abstract}
RESUMO - Este artigo tem como objetivo apresentar o mapeamento das áreas com aptidões ambientais à preservação sob o ponto de vista do meio físico da APA de Santa Rita. Dos mais de $96 \mathrm{~km}^{2}$ de área da unidade de conservação, $67 \mathrm{~km}^{2}$ foram analisados por constituírem a parte terrestre, constituindo a área objeto da análise. Para que isso fosse possível, utilizou-se a técnica de geoprocessamento de álgebra de mapas aliada ao algoritmo de média ponderada. No processo de distribuição dos pesos e notas também foi adotado o método Delphi, buscando o consenso das opiniões dos analistas envolvidos. O resultado da avaliação retornou o mapa sinótico do potencial ambiental à preservação, contendo três classes nominais: Baixo Potencial, abrangendo $35,33 \%$ da área analisada, que se encontra impactada com as atividades antrópicas; Médio Potencial, com 22,99\%, compõe zonas de transição entre os ambientes com maiores e menores potenciais; e Alto Potencial, com 41,68\%, que consiste em áreas de alta fragilidade tanto do meio físico quanto do meio biótico.
\end{abstract}

Palavras-chave: Mapeamento, unidade de conservação, potencial ambiental.

\section{ENVIRONMENTALLY POTENTIAL AREAS FOR PRESERVATION IN SANTA RITA APA: A GEOGRAPHIC APPROACH TO GEOPROCESSING}

\begin{abstract}
This paper aims to present the mapping of areas with environmental preservation skills from the point of view of the physical environment of the Santa Rita APA. Of over $96 \mathrm{~km}^{2}$ area of the protected area, $67 \mathrm{~km}^{2}$ were analyzed, they constitute the inland, thus providing an analysis of the object area. In order to make this possible, we used the maps geoprocessing algebra technique allied to the weighted average algorithm. In the weights and grades distribution process was also adopted the Delphi method, seeking the general opinion agreement of the analysts involved. The evaluation result returned the synoptic map of potential environmental to preservation, containing three rated classes: Low potential, covering $35.33 \%$ of the analyzed area which is impacted by human activities; Medium potential, covering $22.99 \%$, consists transition zones between environments with higher and lower potential; and High potential, covering $41.68 \%$, which are areas of high fragility both physical and biotic environments.
\end{abstract}

Keywords: Mapping, conservation area, environmental potential.

V.2. N.4

DEZEMBRO/2017

P. $91-103$

PÁGINA 91 


\section{INTRODUÇÃO}

O rápido e crescente processo de urbanização no Brasil na última década é reflexo das políticas públicas em prol da diminuição das diferenças entre classes sociais. Estas, a partir de estímulos ao consumo e impulsionadas pelo crescimento econômico a qualquer custo, têm demandado, entre outras necessidades, a aquisição da casa própria. De forma similar, no estado de Alagoas, somente nos últimos seis anos foram licenciados pelo Instituto do Meio Ambiente de Alagoas (IMA/AL) 37 condomínios residenciais e 89 loteamentos, totalizando 126 empreendimentos destas tipologias. Destes, oito situam-se na Área de Proteção (APA) de Santa Rita. Não foram contabilizados os empreendimentos sem licenciamento ambiental e aqueles outorgados por órgãos municipais de meio ambiente.

Com uma demanda crescente de espaços para a construção de empreendimentos desta natureza, o meio natural cede esses espaços tanto de maneira legal quanto ilegal. Observa-se a substituição indiscriminada da cobertura vegetal, bem como a impermeabilização do solo e o lançamento de efluentes líquidos sem tratamento na rede hidrográfica, o que acarreta danos ao meio ambiente e à saúde pública.

A partir da Lei Complementar n. ${ }^{\circ}$ 140/2011 (BRASIL, 2011), que garante aos municípios o licenciamento de empreendimentos (art. $9^{\circ}$, inciso XIV) mediante instrumentos de cooperação, vêm se intensificando os processos de licenciamento ambiental das tipologias anteriormente citadas na APA de Santa Rita, embora a mesma lei excetue o licenciamento ambiental pelos municípios em APA (art. $9^{\circ}$, inciso XIV, alínea b).

Segundo Nascimento, Silva e Guimarães Júnior (2009), uma das ações mais importantes em favor da conservação e preservação da natureza se dá por meio da criação de Unidades de Conservação (UC). Isso tem se tornado possível devido à política ambiental brasileira que instituiu o Sistema Nacional de Unidades de Conservação (SNUC) através da Lei n. ${ }^{\circ}$ 9.985/2000 (BRASIL, 2000), regulamentada pelo Decreto n. ${ }^{\circ}$ 4.340/2002. Entre as diversas modalidades de UC, encontra-se a APA, além de orientações básicas disciplinares para uso sustentável do seu patrimônio natural. O SNUC em seu art. 15 descreve APA como:

[...] uma área em geral extensa, com certo grau de ocupação humana, dotada de atributos abióticos, bióticos, estéticos ou culturais especialmente importantes para a qualidade de vida e o bem-estar das populações humanas, e tem como objetivos básicos proteger a diversidade biológica, disciplinar o processo de ocupação e assegurar a sustentabilidade do uso dos recursos naturais. (BRASIL, 2000).

Com isso, deve haver a compatibilização da ocupação humana com a parcela de seus recursos naturais, o que pode ser entendido como sustentabilidade. Assim, devem-se não só prever as consequências da ocupação e do uso do solo, mas também garantir a representação destas no futuro (ANDRADE; SANTOS, 2007).

Nesse contexto, a APA de Santa Rita foi criada através da Lei n. ${ }^{\circ}$ 4.607/1984 (ALAGOAS, 1984) e regulamentada pelo Decreto n. ${ }^{\circ} 6.274 / 1985$ (ALAGOAS, 1985), com a finalidade de preservar as características ambientais e naturais, ordenando o seu uso do solo. Logo, faz-se necessário buscar o entendimento das dinâmicas antrópicas e naturais na paisagem geográfica, tendo em vista que nas APAs prevalece o domínio privado sobre a terra, porém compete ao poder público ordenar a utilização e a ocupação do território de modo a viabilizar o uso social e ambientalmente responsável das propriedades.

Para isso, o geoprocessamento enquanto ferramenta de apoio e gestão de unidades de conservação dinâmicas, como é o caso das APAs, mostra-se relevante em face de sua concepção pluri e interdisciplinar. Neste sentido, o presente estudo teve como objetivo mapear e identificar 
as áreas que retratam o potencial ambiental ou a vocação natural à preservação ambiental, com base numa abordagem que considera os fatores/características físico-ambientais e antrópicos.

Um dos primeiros entendimentos para a definição da expressão "potencial ambiental" foi definido por Lima et al. (1996), o qual a trata como a identificação das condições do meio físico que se expressam de modo latente, através do qual são identificadas a dimensão e a possibilidade de expansão espacial de um determinado fenômeno natural ou antrópico sobre o meio.

Marino (2008) corrobora com esse entendimento ao afirmar que o potencial ambiental pode ser entendido como um levantamento de condições ambientais no qual são identificadas a extensão e a expansão territorial de um processo ambiental. Para este autor, o termo potencial detém carga semântica ambígua, capaz de expressar conotações positivas ou negativas. Exemplo de teor negativo é o potencial de uma área propícia a abrigar aglomerados subnormais. A conotação positiva se dá através de regiões com aptidão ao reflorestamento.

Souza, Botelho e Lisbôa (2012) colaboram na definição do termo áreas potenciais, com uma abordagem biogeográfica, onde tratam como as áreas favoráveis à distribuição espaço-temporal de um determinado fenômeno.

De modo geral, o mapa de "potencialidade" ou "potenciais" deve ser elaborado a partir de um inventário ambiental, correspondendo a mapas temáticos de uma determinada área geográfica sobre a qual são realizadas integrações com o intuito de estimar aptidões ou condições ambientais positivas de interesses para o planejamento e a gestão territoriais - neste caso, especificamente, a necessidade de preservação de partes do território da APA de Santa Rita.

Com isso, foi elaborado um cenário de preservação do meio, assumindo como base a adequabilidade do terreno da APA em função das suas características físicas - como a litologia, declividade, altitude, pedologia e geomorfologia; da influência da ação antrópica - como o uso e a ocupação do solo; e das características naturais da paisagem - a exemplo da cobertura vegetal.

\section{ÁREA DE ESTUDO}

A Área de Proteção Ambiental (APA) de Santa Rita (Figura 1) abrange partes dos municípios de Maceió, Marechal Deodoro e Coqueiro Seco, estendendo-se entre as coordenadas geográficas $09^{\circ} 31^{\prime} 39^{\prime \prime}$ e $09^{\circ} 37^{\prime} 16^{\prime \prime}$ de latitude sul, e $35^{\circ} 45^{\prime} 32^{\prime \prime}$ e $35^{\circ} 49^{\prime} 19^{\prime \prime}$ de longitude oeste. Ocupa uma área de 9.638,79 hectares, o que corresponde a $96,39 \mathrm{~km}^{2}$, circunscritos em um perímetro de 113,90 quilômetros. Ao desconsiderar os corpos d'água das lagunas Mundaú e Manguaba e do oceano Atlântico, contabiliza-se uma área de $6.711,73$ ha $\left(67,12 \mathrm{~km}^{2}\right)$.

Inserida na porção central do litoral alagoano, localizado na região Nordeste do Brasil, portanto, na Zona Tropical, a área objeto está sob influência do clima subúmido, segundo a classificação de Thornthwaite que tem como característica a temperatura que varia entre 21 e $30^{\circ} \mathrm{C}$, com precipitação concentrada no outono e inverno, entre os meses de maio e agosto, sendo junho e julho os meses mais úmidos, e novembro e dezembro os mais secos. O índice pluviométrico que abrange a APA varia entre as faixas de 1.700 a $1.900 \mathrm{~mm} /$ ano (EMPRESA BRASILEIRA DE PESQUISA AGROPECUÁRIA, 2012).

O relevo é constituído pelos Tabuleiros Costeiros, que consistem nas falésias fósseis, cobertas pela vegetação típica de Mata Atlântica nas áreas declivosas e pela Planície Costeira, formada pelos sedimentos quaternários de praia e aluvião, compondo as áreas de restinga, os alagadiços de mangue, terraços fluviolagunares, as praias e os cordões arenosos. As cotas variam de 0 metro ao nível do mar até 100 metros. Nas faixas altimétricas mais baixas - de 0m a $20 \mathrm{~m}$ - situam-se os usos e ocupações do solo mais intensos, como a especulação imobiliária e atividades agrícolas, além de remanescentes de vegetação de restinga e 
manguezais; já nas cotas mais altas são verificados os remanescentes de Mata Atlântica de encosta e a monocultura da cana-de-açúcar.

Figura1 - Localização da área de estudo.

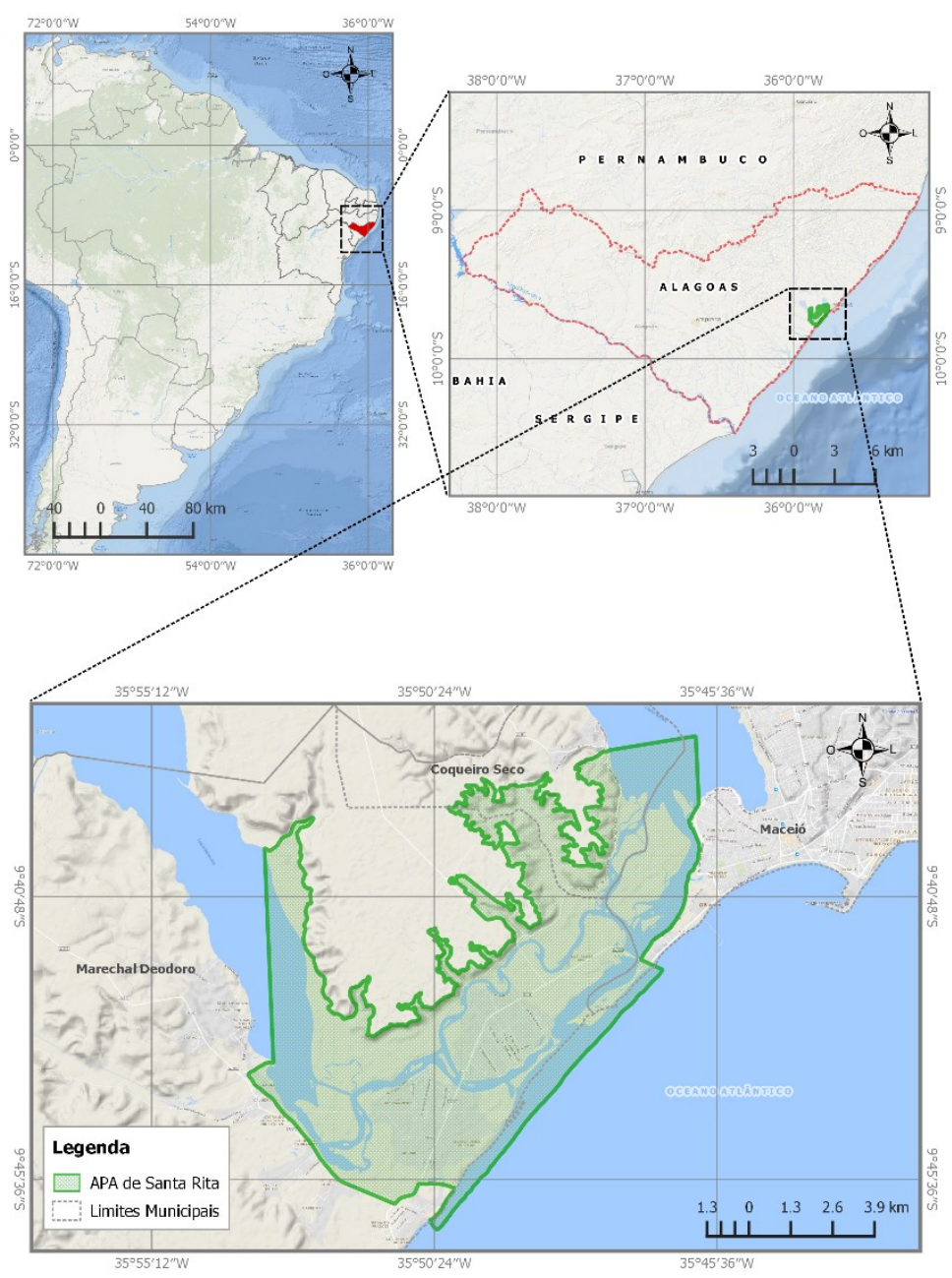

\section{METODOLOGIA}

A metodologia empregada se alicerça na investigação combinada de atributos espaciais e não espaciais, a fim de gerar um mapa síntese como produto final. Tais atributos e dados geográficos são os elementos constituintes de uma determinada área; por exemplo, o clima, o relevo, os solos, a vegetação, as plantações e as cidades. No geoprocessamento, esses fenômenos são denominados de "variáveis" ou "planos de informação".

As variáveis utilizadas para construir o mapa síntese de potencial à preservação ambiental através da integração entre si foram: a) Solos; b) Litologia; c) Declividade; d) Hipsometria; e) Geomorfologia e f) Uso do Solo e Cobertura Vegetal.

A integração entre as variáveis selecionadas corresponde à avaliação ambiental, conforme descrito anteriormente. Ao integrá-las diretamente, o processo é denominado de "integração simples" ou "avaliação direta". O cruzamento das variáveis é feito de forma direta, isto é, sobre os dados originais. 
Além das técnicas de geoprocessamento, neste trabalho também foi utilizado o método Delphi no processo de distribuição dos pesos aos parâmetros e na aplicação de notas às categorias de cada parâmetro utilizado, buscando-se o consenso das opiniões do grupo.

A aplicação deste método é recomendável quando não se dispõe de dados quantitativos predefinidos que qualifiquem o objeto estudado. A técnica baseia-se no uso estruturado do conhecimento e da experiência do grupo de estudo, pressupondo que a opinião coletiva, quando organizada adequadamente, é melhor que a opinião de um único indivíduo (WRIGHT; GIOVINAZZO, 2000).

O estudo baseou-se na análise de critérios múltiplos, a qual se alicerça na investigação combinada de atributos espaciais a fim de gerar um mapa síntese como produto final. Tal análise fundamentase na integração ou combinação dos dados geográficos construídos para esta finalidade, através do emprego de expressões matemáticas, o que configura o termo álgebra de mapas.

A álgebra de mapas consiste na aplicação de operações aritméticas para associar várias camadas (mapas temáticos) de modo a obter como resultado classificações que permitem análises diversas. A análise de multicritério com o método de álgebra de mapa possibilita agrupar e classificar áreas que apresentem vocação para a preservação ambiental.

A escala definida para a elaboração dos planos de informação foi de 1:50.000, baseada na cartografia do Instituto Brasileiro de Geografia e Estatística (1985), através da Carta Topográfica da Região Nordeste do Brasil, folha Pilar (SC.25-V-C-IV-1). A resolução espacial admitida foi de 10 metros, ou seja, cada célula disposta nos mapas corresponde a uma unidade territorial de $10 \mathrm{~m}$, ou $100 \mathrm{~m}^{2}$.

De acordo com Calheiros (1993), a avaliação ambiental consiste no cruzamento dos mapas, utilizando-se média aritmética ponderada; cada mapa é ponderado pela utilização de pesos, segundo sua importância relativa. Postula-se que o conjunto de mapas compõe $100 \%$ da responsabilidade pela situação ambiental analisada. As classes recebem notas (de 0 a 10), segundo a possibilidade de associação da classe com a ocorrência do fenômeno estudado. Daí resulta um mapa final que expressa as áreas com potenciais para determinado objetivo em escala ordinal.

O algoritmo utilizado se expressa através da seguinte equação:

$A_{i j}=\sum_{k=1}\left(P_{k} \cdot N_{k}\right)$

(Equação 1)

Onde:

$\mathrm{A}_{\mathrm{ij}}=$ célula qualquer da matriz

$\mathrm{n}=$ número de parâmetros envolvidos

$\mathrm{P}=$ peso atribuído do parâmetro, no intervalo de 0 a 1

$\mathrm{N}=$ nota atribuída à categoria encontrada na célula da matriz ( 0 a 10)

As notas atribuídas às classes do mapa variaram de 0 a 10 . Estabeleceu-se que as classes com uma participação nula receberiam nota 0 . As classes com participação quase nula na ocorrência do fenômeno estudado receberiam nota 1 e 2 . As classes com uma pequena participação receberiam notas de 3 a 4. Para aquelas com participação média, as notas variariam entre 5 e 6 . Aquelas com grande participação, entre 7 e 8 . Às classes onde as ocorrências eram muito possíveis e extremamente possíveis, foram atribuídas as notas 9 e 10 , respectivamente.

Os pesos e notas foram atribuídos com base no conhecimento teórico e prévio da área em estudo, e também nas observações empíricas, visando calibrar os pesos e notas, e finalmente atingir um produto próximo à realidade. 


\section{RESULTADOS E DISCUSSÃO}

Os resultados obtidos a partir da análise das variáveis inventariadas da literatura existente e do conhecimento empírico da área de estudo permitiram identificar fenômenos como a ocupação urbana em áreas sujeitas a alagamento; o solo desnudo em decorrência da cobertura vegetal nativa; áreas agricultadas em terreno com inclinação desfavorável. Mencionam-se apenas essas situações como exemplos de conflitos dos interesses e necessidades humanas com o meio, que é quem provê tais demandas.

A Lei n. ${ }^{\circ}$ 6.938/81 (BRASIL, 1981), que institui a Política Nacional do Meio Ambiente (PNMA), considera o meio ambiente como patrimônio público a ser necessariamente assegurado e protegido, tendo em vista o seu uso coletivo, devendo-se racionalizar os usos do solo, do subsolo, da água e do ar. Para isso é necessária a proteção dos ecossistemas com a preservação das áreas representativas e das áreas ameaçadas da degradação.

Neste contexto, as variáveis foram ponderadas levando em consideração a representatividade de suas participações na preservação do meio físico como base para o estabelecimento dos meios bióticos e abióticos, e o grau de possibilidade de ocorrência de cada categoria das variáveis no tema estudado.

Desta forma, a litologia recebeu um peso de $10 \%$ na sua participação na avaliação, devido à formação e à composição inconsolidada das rochas, típicas da geologia sedimentar dos períodos terciário e quartanário (Tabela 1). A maior nota para os Sedimentos de Praia e Aluvião se deveu à sua maior representatividade espacial na área de estudo e por ser de idade mais recente, portanto, mais frágil em relação aos Sedimentos da Formação Barreiras.

Tabela 1 - Notas atribuídas para as categorias inerentes à variável Litologia

\begin{tabular}{|c|c|c|}
\hline LITOLOGIA & Peso 10\% & Grau de \\
\hline Classes & Notas & Possibilidade \\
\hline Sedimentos Quaternários de Praia e Aluvião & 7 & Alto \\
\hline Sedimentos Terciários da Formação Barreiras & 6 & Médio \\
\hline
\end{tabular}

No que se refere à declividade (Tabela 2), esta tem relação direta em processos erosivos no relevo, na velocidade de escoamento das águas pluviais e na taxa de percolação das águas no solo.

A participação desta variável na avaliação teve como peso $17,5 \%$, por considerar sua relevância enquanto Áreas de Preservação Permanente (APPs) de encostas, sendo atribuídas as notas mais altas para as classes com maior clinometria.

Tabela 2 - Notas atribuídas para as categorias inerentes à variável Declividade

\begin{tabular}{lcc}
\hline \multicolumn{1}{c}{ DECLIVIDADE } & Peso 17,5\% & Grau de \\
\cline { 1 - 2 } Classes & Notas & \\
Possibilidade
\end{tabular}

A altitude, por sua vez, reflete se uma área apresenta, ou não, condições de ocupação em faixas altimétricas propícias para tal (Tabela3). O peso de $10 \%$ divide sua relevância com a 
declividade, tendo, portanto, participação complementar na avaliação. As cotas mais altas aliadas à declividade formam condições de grande relevância para a preservação desses ambientes sensíveis à estabilização dos solos e, por consequência, evitam risco de deslizamentos e soterramento de núcleos urbanos e atividades econômicas. Por esses motivos, as altitudes acima de 60 metros foram consideradas como de alto e altíssimo grau de possibilidade à preservação.

Tabela 3 - Notas atribuídas para as categorias inerentes à variável Altitude

\begin{tabular}{lccc}
\hline & ALTITUDE & Peso 10\% & Grau de \\
\cline { 1 - 2 } & Classes & Notas & Possibilidade \\
\hline $0-10 \mathrm{~m}$ & & 3,5 & Baixo \\
$10-20 \mathrm{~m}$ & & 4,5 & Baixo \\
$20-30 \mathrm{~m}$ & & 6 & Médio \\
$30-40 \mathrm{~m}$ & & 6,5 & Médio \\
$40-50 \mathrm{~m}$ & & 7 & Médio \\
$50-60 \mathrm{~m}$ & & 8,5 & Médio \\
$60-70 \mathrm{~m}$ & & 8 & Alto \\
$70-80 \mathrm{~m}$ & & 8,5 & Alto \\
$80-90 \mathrm{~m}$ & & 9,5 & Altíssimo \\
$90-100 \mathrm{~m}$ & & 9,5 & Altíssimo \\
\hline
\end{tabular}

Em se tratando de pedologia, sua participação foi de 15\% (Tabela-4), em virtude de fatores como profundidade, porosidade, permeabilidade, fertilidade, plasticidade e textura serem considerados importantes para a estabilidade e preservação de ambientes mais suscetíveis ao transporte de líquidos, tanto superficial quanto subsuperficial, à erosão e à distância para o lençol freático, além da sua abrangência geográfica.

As maiores notas foram distribuídas para os neossolos quartzarênicos, os espodossolos e os gleissolos, Os dois primeiros solos são mais recentes, com características arenoquartzosas, portanto, friáveis, e não possuem aptidão agrícola devido à baixa fertilidade.

Os gleissolos, por sua vez, estão sob a influência de oscilações de maré, portanto, são mal drenados e possuem alto risco de ocorrência de inundações. Tais notas se acham entre os graus de possibilidade médio e alto à preservação.

Tabela 4 - Notas atribuídas para as categorias inerentes à variável Solos

\begin{tabular}{lccc}
\hline \multicolumn{1}{c}{ SOLOS } & Peso $15 \%$ & \multirow{2}{*}{ Grau de Possibilidade } \\
\cline { 1 - 2 } & Notas & & Baixo \\
Argissolos + Gleissolos Melânicos + Luvissolos & 3,5 & & Baixo \\
Argissolos Vermelho-Amarelos + Latossolos & 4,5 & & Alto \\
Vermelho-Amarelos & 7 & Alto \\
Gleissolos Melâlnicos & 7,5 & Médio \\
Gleissolos Tiomórficos & 6 & Médio \\
Neossolos Quartzarênicos & 6,5 & \\
Neossolos Quartzarênicos + Espodossolos & & \\
\hline
\end{tabular}

O relevo presente na área de estudo, representado aqui pela geomorfologia, é considerado pouco diferenciado, detendo majoritariamente a unidade da planície litorânea e minoritariamente os tabuleiros costeiros. 
Esta variável recebeu um peso de $25 \%$ por representar a ação humana como catalisadora dos processos morfodinâmicos atuais na morfologia da paisagem (Tabela 5).

Receberam as maiores notas aquelas feições que se apresentam mais suscetíveis às interferências antrópicas, podendo gerar desequilíbrios morfológicos ou impactos geoambientais.

Tabela 5 - Notas atribuídas para as categorias inerentes à variável Geomorfologia

\begin{tabular}{lccc}
\hline \multicolumn{1}{c}{ GEOMORFOLOGIA } & Peso 25\% & \multirow{2}{*}{ Grau de Possibilidade } \\
\cline { 1 - 2 } Alagadiços de Maré/Vazas Fluviolagunares & Notas & \\
Encostas de Estuário Lagunar & 10 & Altíssimo \\
Encosta de Vale Fluvial & 9 & Altíssimo \\
Falésia Fóssil & 9 & Altíssimo \\
Praia Oceânica & 9,5 & Altíssimo \\
Rampas de Colúvio & 4 & Baixo \\
Recifes & 6,5 & Médio \\
Terraços Colúvio-Aluvionais & 9,5 & Altíssimo \\
Terraços Fluviomarinhos, Lagunares e Cordões & 7 & Alto \\
Praias & 6 & Médio \\
Terraços Marinhos e Cristas Praiais & 5,5 & Médio \\
Vales Fluviais Decapitados & 8 & Alto \\
Várzea Fluvial & 8 & Alto \\
Várzea Fluviolagunar & 8,5 & Alto \\
\hline
\end{tabular}

O uso do solo e a cobertura vegetal representam $25 \%$ de importância na avaliação realizada (Tabela 6). Isto se deve, primordialmente, por apresentar um registro espacial e temporal da composição paisagística no ambiente analisado. Ela reflete basicamente os tipos de ocupações e usos na APA.

As partições do terreno que ainda cumprem função ecológica, que se configuram em ecossistemas fechados, de que restam parcos fragmentos espaciais ou que sofreram pouca ou nenhuma intervenção humana obtiveram as maiores notas, a exemplo dos manguezais, da vegetação arbórea de restinga e das pioneiras fluviolagunares.

Ao contrário, receberam as menores notas aquelas áreas com níveis de antropização considerados de avançados a definitivos; por exemplo, canaviais, coqueirais e sítios urbanos, respectivamente.

Tabela 6 - Notas atribuídas para as categorias inerentes à variável Uso do Solo e Cobertura Vegetal

\begin{tabular}{lccc}
\hline USO DO SOLO E COBERTURA VEGETAL & Peso 25\% & \multirow{2}{*}{ Grau de Possibilidade } \\
\cline { 1 - 2 } Manguezal & Notas & \\
Apicum & 10 & Altíssimo \\
Áreas Alagadas/Veredas & 9 & Altíssimo \\
Área Urbanizada/Edificada & 8,5 & Alto \\
Balneário & 1 & Baixíssimo \\
Bambuzal & 5 & Médio \\
Campo Limpo & 4,5 & Baixo \\
Canavial & 5 & Médio \\
Coqueiral & 1 & Baixíssimo \\
Coqueiral Associado a Frutíferas & 1,5 & Baixíssimo \\
Coqueiral Associado a Lavouras & 3 & Baixo \\
& 2 & Baixíssimo
\end{tabular}




\begin{tabular}{lcc} 
Coqueiral Associado a Apicum & 4,5 & Médio \\
Croa & 4 & Baixo \\
Erosão & 5 & Médio \\
Pomares/Frutíferas & 4,5 & Baixo \\
Lagoas & 8,5 & Alto \\
Lavouras de Subsistência & 3 & Baixo \\
Floresta Ombrófila Densa de Encosta & 10 & Altíssimo \\
Pasto & 2 & Baixíssimo \\
Pioneiras Fluviolacustres/Macega & 10 & Altíssimo \\
Psicultura & 1 & Baixíssimo \\
Praias & 4,5 & Baixo \\
Recifes & 10 & Altíssimo \\
Reserva Ecológica do Saco da Pedra & 8 & Alto \\
Mata de Restinga & 9 & Altíssimo \\
Solo Exposto & 2,5 & Baixíssimo \\
Vegetação em Estágio de Sucessão Natural & 8,5 & Alto \\
\hline
\end{tabular}

\section{AVALIAÇÃO DO POTENCIAL DE PRESERVAÇÃO}

A avaliação ambiental resultou no mapa sinótico de potencial de preservação (Figura 2), contendo oito classes correspondentes às notas alcançadas, que variaram de 3 a 8 . Essas foram reclassificadas em quatro, passando da escala ordinal para a nominal, de maneira que representassem cartograficamente os níveis/graus de potencialidade. Para isto, definiu-se o seu agrupamento com base nas proximidades dos valores das notas, nominando-os, por conseguinte, como baixo, médio e alto. Não foram verificadas as notas 0,1 e 2, nem 9 e 10 . Desta forma, não houve áreas com baixíssimo ou altíssimo potencial.

A Tabela 7 apresenta as classes com suas respectivas planimetrias e percentagens sobre a área analisada.

Tabela 7 - Resultado da avaliação para as áreas com potencial para preservação

\begin{tabular}{cccc}
\hline NOTAS & CLASSES & ÁREA (Ha) & ÁREA (\%)* \\
\hline 3 e 4 & Baixo & 2.445 & 35,33 \\
5 e 6 & Médio & $1.591,35$ & 22,99 \\
7 e 8 & Alto & $2.884,93$ & 41,68 \\
\hline
\end{tabular}

(*) Área total da presença do potencial em relação à área terrestre analisada.

O Baixo Potencial abrange uma área de 2.445 hectares, correspondendo a 35,33\% da área terrestre da APA de Santa Rita. Localiza-se predominantemente em três porções areais. A primeira, na porção central da área de estudo, especificamente na ilha homônima desta unidade de conservação; a segunda estende-se do primeiro no sentido sul, na Massagueira; e a terceira, a sudoeste, abrange as localidades Assobio, Ribeira, Outeiro, Cumbe e Riacho Velho.

Esta classe compreende um relevo plano que não ultrapassa a cota de 10 metros, formando em sua maioria os terraços fluviomarinhos, lagunares e os cordões praiais, todos estabelecidos sobre uma litologia recente e inconsolidada do período geológico quaternário, nominada de Sedimentos de Praia e Aluvião, a qual propicia uma pedologia baseada nos neossolos quartzarênicos e nos espodossolos. Nesta conformação, as ocupações e os usos dados ao solo se constituíram historicamente na região como os sítios de coqueirais, lavouras de subsistência e, mais recentemente, a urbanização. 
Figura 2 - Áreas potenciais para preservação ambiental.

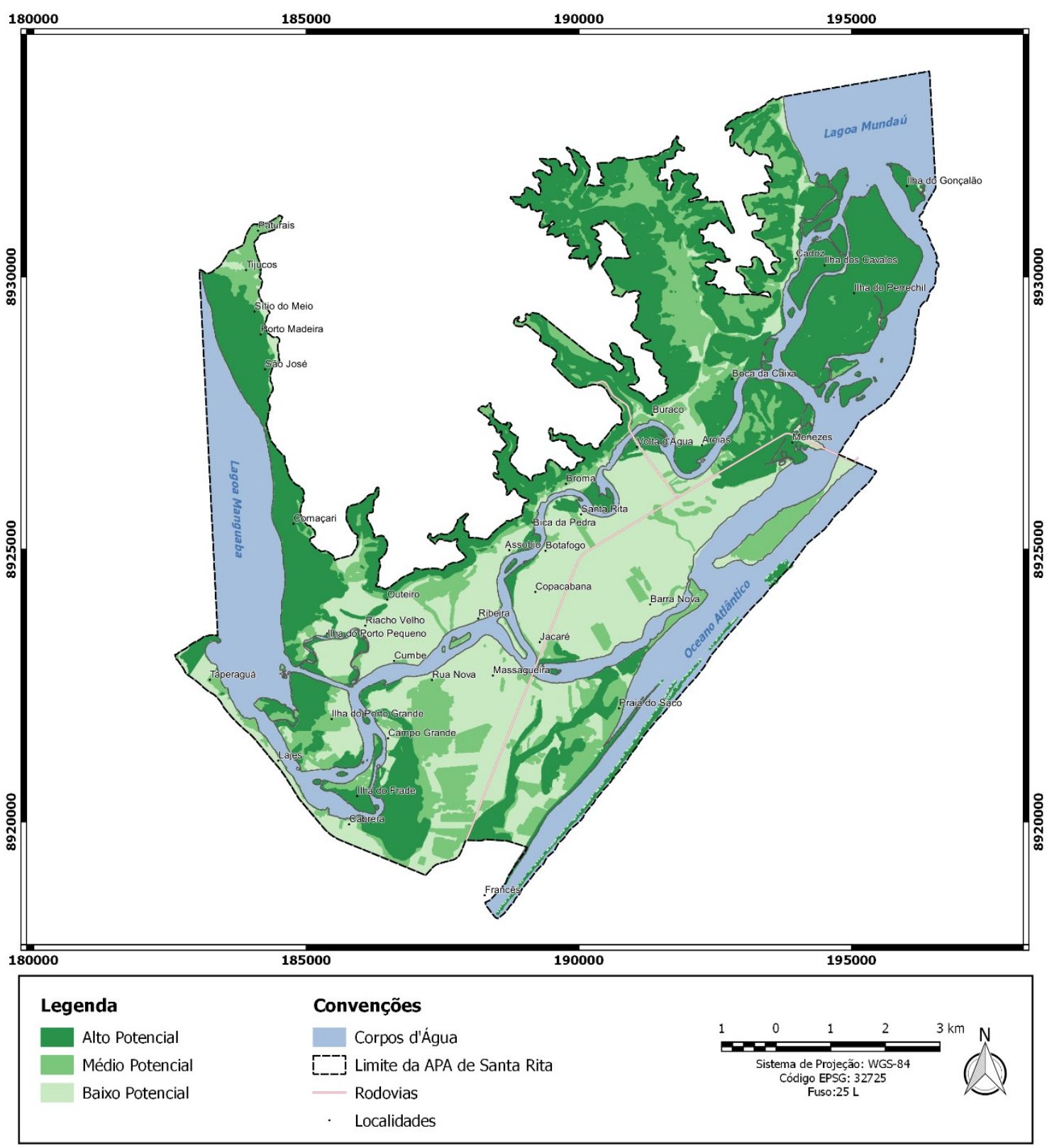

Do ponto de vista da preservação ambiental, recomenda-se deixar esses espaços na situação em que se encontram, uma vez que pouco mais de $1 / 3$ das áreas terrestres da APA já se encontram impactadas com as atividades antrópicas acima mencionadas. Entre as categorias de usos e ocupações, a que mais pode comprometer o equilíbrio e a função ecológica da APA de Santa Rita é a urbanização, em virtude da alta taxa de impermeabilização do solo e da saturação do subsolo com efluentes. Quanto aos coqueirais, embora sejam uma tipologia antrópica de uso da terra, eles se encarregam de manter a permeabilidade do solo, além de agregar valor cênico à paisagem.

O Médio Potencial compartimenta-se em dois ambientes: na planície litorânea e nas encostas do tabuleiro costeiro. Totaliza uma área de 1.591,35 hectares, o que representa $22,99 \%$ da área total analisada, contendo ao menos sete relevantes aglomerados.

Na planície, este potencial se expressa: a) no fundo do vale do rio dos Remédios, próximo à localidade Boca da Caixa, norte da área estudada; b) no extremo leste da APA, especificamente 
no esporão arenoso do Pontal da Barra em Maceió, também conhecido como restinga do Detran; c) no Saco da Pedra, sudeste da área de estudo; d) no Mucuri, na parte sul, entre a Massagueira e a rotatória do Francês; e e) nas imediações da rua Nova, entre a Massagueira e o canal de dentro do Sistema Estuarino Lagunar Mundaú-Manguaba (SELMM).

Em todas essas áreas a litologia é sedimentar de praia e aluvião, em terreno plano, com declividade que não ultrapassa os $3 \%$ ou $1,9^{\circ}$. Esta declividade se estende em faixas altimétricas de 0 a 10metros, contendo neossolos quartzarênicos e espodossolos, típicos de cordões praiais, terraços marinhos e terraços fluviomarinhos e lagunares, respectivamente.

Influenciou decisivamente na constituição deste nível de potencial a cobertura vegetal dominante nos ambientes, como os resquícios de floresta estacional semidecidual (restinga em porte arbóreo) e as pioneiras fluviomarinhas.

Nas encostas, o Médio Potencial se manifesta: f) no extremo norte da área estudada, no trecho compreendido entre o riacho da Bernardina e o povoado Cadoz, passando pela localidade Areias, próximo ao canal de dentro do SELMM; g) na porção centro-oeste da APA de Santa Rita, nas encostas do Broma, Bica da Pedra e Outeiro.

Nesses ambientes a litologia corresponde à Formação Barreiras, formada preponderantemente pelas rampas de colúvio e partes mais baixas dos vales fluviais decapitados, com uma declividade que varia de suave ondulada a ondulada (3\% a $20 \%$ ), o que corresponde a uma inclinação entre $1,9^{\circ}$ e $12,6^{\circ}$. Os solos característicos destes lugares são os argissolos vermelhoamarelos em maior proporção e, em menor escala, os latossolos vermelho-amarelos.

Atuaram decisivamente na composição deste potencial, além dos parâmetros acima descritos, a fitofisionomia da floresta ombrófila de encosta.

Ao analisar esse cenário de médio potencial, nota-se que são ambientes frágeis, em situação de pouca intervenção antrópica ou na sua iminência. Compõem zonas transicionais entre os ambientes com maiores e menores potenciais de preservação. Isto se deve em muito ao efeito da persistência dos fragmentos vegetacionais nas áreas.

O Alto Potencial detém uma expressão espacial de 2.884,93 hectares, representando 41,68\% da área terrestre, objeto deste trabalho. Apresenta-se disposto massivamente: a) no extremo nordeste da área em apreciação, especificamente na localidade Menezes e nas ilhas do Perrechil, dos Cavalos e do Gonçalo; b) ao norte e centro-norte, nas porções 3/4 superiores das encostas do vale do rio dos Remédios, Broma, Bica da Pedra e Outeiro, respectivamente; c) a noroeste, em toda a planície e encosta fluviolagunar, indo desde as localidades de Gomaçari até Paturais; e d) ao sul e sudeste, no entorno das localidades Campo Grande e Massagueira de Baixo, respectivamente.

$\mathrm{Na}$ porção nordeste, predominam as terras baixas, de relevo plano e morfologia majoritariamente de Alagadiços de Maré, possuindo uma pedologia tipifcada de ambientes palustres, ou seja, os gleissolos tiomórficos. Preponderam nestes locais densos bosques de manguezais que cumprem importantes funções ecológica e social.

$\mathrm{Na}$ parte norte, as faixas altimétricas compreendidas entre 40 e 100 metros, associadas à declividade forte ondulada a montanhosa $\left(20 \%\right.$ a $75 \%$, correspondente a $12,6^{\circ}$ a $\left.41^{\circ}\right)$ e aos remanescentes de floresta ombrófila, se estabelecem sobre um relevo composto de rampas de colúvio, vales fluviais decapitados e falésias fósseis. Estes constituem ambientes suscetíveis a desequilíbrios morfológicos como os movimentos de massa, que podem causar impactos geoambientais, assim como soterramentos e assoreamentos.

Na parcela noroeste da área estudada, onde a declividade é considerada plana e está distribuída entre as cotas altimétricas de 0 a 10 metros, verifica-se uma associação discriminada entre os 
gleissolos melânicos e os tiomórficos, sobre uma litologia sedimentar aluvional, compondo feições paisagísticas de várzea fluviolagunar e alagadiços de maré. Com essas características geoambientais, formam-se condições favoráveis ao estabelecimento de vegetação pioneira fluviolacustre e de mangues.

Nas porções sul e sudeste, a morfologia dos terrenos favorece essas áreas como Alto Potencial devido aos solos serem típicos de charcos e se acharem sob a influência de oscilações de maré, possuindo alto risco de inundações. Nessa conjunção, observam-se ecossistemas típicos de apicum, mangue e alagadiços.

Este nível de potencial consiste em áreas de alta fragilidade tanto do terreno quanto da flora e da fauna sobre ele estabelecidas. Tal fragilidade também pode ser convertida em suscetibilidade a riscos ao meio, ao patrimônio e até à vida, numa eventual substituição das ocupações naturais por outros usos/ocupações humanos/as.

\section{CONCLUSÕES}

A avaliação ambiental constitui-se numa primeira instância de investigação da paisagem, a qual se empenha em identificar áreas propícias ou com probabilidades de ocorrência da preservação, levando em conta suas características geoambientais.

Por se tratar de uma análise preliminar que visa ao planejamento ambiental da APA de Santa Rita, as avaliações e suas respectivas análises devem chegar à exaustão através de estudos orientados à identificação de áreas conflituosas, incongruências de uso do solo, áreas de riscos socioambientais e áreas críticas, entre outras.

Para isso, faz-se imprescindível o investimento de recursos financeiros, tecnológicos e humanos na construção de bases de dados e informações, a fim de criar as condições propícias e necessárias à gestão ambiental da unidade de conservação.

Os resultados obtidos na avaliação de áreas com potencial ambiental à preservação apresentaram-se condizentes com a realidade observada e identificada empiricamente, aproximando-se dos números correspondentes ao zoneamento do plano de manejo da APA.

A tecnologia de Sistemas Geográficos de Informação apresentou uma visão integradora, consistindo num poderoso instrumento de análise ambiental para a tomada de decisão.

\section{REFERÊNCIAS}

ALAGOAS. Decreto n ${ }^{\circ}$ 6.274, de 5 de junho de 1985. Dispõe sobre a Área de Proteção Ambiental de Santa Rita, cria a Reserva Ecológica do Saco da Pedra e dá providências correlatas. Diário Oficial do Estado de Alagoas, Maceió, 8 jun. 1985.

Lei no 4.607, de 19 de dezembro de 1984. Cria a Área de Proteção Ambiental e dá outras providências. Diário Oficial do Estado de Alagoas, Maceió, 20 dez. 1983.

ANDRADE, E. de L.; SANTOS, A. L. S. Plano de recuperação de áreas degradadas das matas ciliares dos principais corpos hídricos: área de proteção ambiental do Catolé e Fernão Velho: relatório técnico. Maceió: [s.n.], 2007. 50 p.

BRASIL. Decreto 4.340, de 22 de agosto de 2002. Regulamenta artigos da Lei no 9.985, de 18 de julho de 2000, que dispõe sobre o Sistema Nacional de Unidades de Conservação da Natureza -SNUC, e dá outras providências. Diário Oficial [da] República Federativa do Brasil, Brasília, DF, 23 ago. 2002. p. 9.

Lei ${ }^{\circ} 9.985$, de 18 de janeiro de 2000. Regulamenta o art. 225, § $1^{\circ}$, incisos I, II, III e VII da Constituição Federal, institui o Sistema Nacional de Unidades de Conservação da Natureza e dá outras providências. Diário Oficial [da] República Federativa do Brasil, Brasília, DF, 19 jul. 2000. 
Lei $\mathrm{n}^{\circ}$ 6.938, de 31 de agosto de 1981. Dispõe sobre a Política Nacional do Meio Ambiente, seus fins e mecanismos de formulação e aplicação, e dá outras providências. Diário Oficial da União, Brasília, DF, 2 set. 1981. p. 16.509.

Lei Complementar $n^{\circ} 140$, de 8 de janeiro de 2011. Fixa normas, nos termos dos incisos III, VI e VII do caput e do parágrafo único do art. 23 da Constituição Federal, para a cooperação entre a União, os Estados, o Distrito Federal e os Municípios nas ações administrativas decorrentes do exercício da competência comum relativas à proteção das paisagens naturais notáveis, à proteção do meio ambiente, ao combate à poluição em qualquer de suas formas e à preservação das florestas, da fauna e da flora; e altera a Lei $n^{\circ}$ 6.938, de 31 de agosto de 1981. Diário Oficial [da] República Federativa do Brasil, Brasília, DF, 9 dez. 2001. p. 1.

CALHEIROS, S. Q. C. Impactos na cobertura vegetal no Complexo Estuarino Lagunar MundaúManguaba de 1965 a 1989/90. 1993. 135 f. Dissertação (Mestrado em Geografia) - Universidade Estadual Paulista “Julio de Mesquita Filho”, Instituto de Geociência e Ciências Exatas, Rio Claro, 1993.

COMISSÃO MUNDIAL SOBRE MEIO AMBIENTE E DESENVOLVIMENTO (CMMAD). Nosso futuro comum. 2. ed. Rio de Janeiro: Editora da Fundação Getúlio Vargas, 1991. Tradução de: Our common future.

EMPRESA BRASILEIRA DE PESQUISA AGROPECUÁRIA. Centro Nacional de Pesquisa de Solos. Unidade de Execução de Pesquisa e Desenvolvimento em Recife. Mapa pluviométrico do estado de Alagoas. In: Zoneamento agroecológico de Alagoas. Recife: Convênio SEAGRIAL/EMBRAPA. Solos, nº 10200.09/0134-5, 2012.

INSTITUTO BRASILEIRO DE GEOGRAFIA E ESTATÍSTICA (IBGE). Mapas Base dos municípios do Estado de Alagoas. Rio de Janeiro, Escalas variadas.

LIMA, L. M. C. A. et al. Maceió: potencial turístico com base na tecnologia de sistema geográfico de informação. In: I SEMANA ESTADUAL DE GEOPROCESSAMENTO - RJ, 1., 1996, Rio de Janeiro. Geoprocessamento: Mitos \& Realidade. Rio de Janeiro: FGeoRJ, 1996. P. 1-14. Disponível em: $<$ https://goo.gl/oUczjd $>$. Acesso em: 12 out. 2016.

MARINO, T. B. Metodologia para tomadas de decisão no âmbito de riscos sócio-ambientais de áreas urbanas: desmoronamentos e enchentes em assentamentos precários na bacia do Córrego Cabuçu de Baixo - SP. 2008. 138 f. Dissertação (Mestrado em Engenharia) - Escola Politécnica da Universidade de São Paulo, Departamento de Engenharia de Transportes, São Paulo, 2008. 138 p.

NASCIMENTO, M. C. do; SILVA, M. P. da; GUIMARÃES JÚNIOR, S. A. M. Geoprocessamento aplicado a análise dos impactos ambientais na cobertura vegetal da Área de Proteção Ambiental de Santa Rita, AlagoasBrasil. In: SIMPÓSIO BRASILEIRO DE SENSORIAMENTO REMOTO, 14., Natal, 2009. Anais... São José dos Campos: INPE, 2009. p. 4.101-4.108.

SOUZA, F. S. de; BOTELHO, M. C. S. N.; LISBÔA, R. S.. Aplicações do geoprocessamento na análise da distribuição espaço-temporal de áreas potenciais à ocorrência simultânea de dermatobiose e carrapato Rhipicephalus microplus em bovino no município de Seropédica, RJ, Brasil. Arquivos do Instituto Biológico, São Paulo, v. 1, n. 79, p. 17-23, mar. 2012. Trimestral. Disponível em: $<$ https://goo.gl/5vj8oW>. Acesso em: 01 nov. 2016.

WRIGHT, J. T. C.; GIOVINAZZO, R. A. Delphi - uma ferramenta de apoio ao planejamento prospectivo. Caderno de Pesquisas em Administração, São Paulo, v. 1, n. 12, abr./maio, p. 54-65, 2000. 